\title{
Relation of High Lipoprotein (a) Concentrations to Platelet Reactivity in Individuals with and Without Coronary Artery Disease
}

\author{
Rocío Salsoso (D) - Talia F. Dalcoquio • Remo H. M. Furtado · André Franci - Carlos J. D. G. Barbosa • \\ Paulo R. R. Genestreti · Celia M. C. Strunz • Viviane Lima • Luciano M. Baracioli • \\ Robert P. Giugliano · Shaun G. Goodman · Paul A. Gurbel · Raul C. Maranhão · Jose C. Nicolau
}

Received: June 13, 2020 / Published online: September 5, 2020

(C) The Author(s) 2020

\section{ABSTRACT}

Introduction: Lipoprotein $(a)[\operatorname{Lp}(a)]$ is a risk factor for coronary artery disease (CAD). To the best of our knowledge, this is the first study addressing the relationship between $\operatorname{Lp}(a)$ and

Digital Features To view digital features for this article go to https://doi.org/10.6084/m9.figshare.12815906.

Electronic supplementary material The online version of this article (https://doi.org/10.1007/s12325020-01483-y) contains supplementary material, which is available to authorized users.

R. Salsoso - T. F. Dalcoquio - R. H. M. Furtado .

A. Franci - C. J. D. G. Barbosa - P. R. R. Genestreti

C. M. C. Strunz · V. Lima · L. M. Baracioli .

J. C. Nicolau ( $\square)$

Faculdade de Medicina, Instituto do Coracao

(InCor), Hospital das Clinicas HCFMUSP,

Universidade de Sao Paulo, São Paulo, SP, Brazil

e-mail: jose.nicolau@incor.usp.br

R. H. M. Furtado

Hospital Israelita Albert Einstein, Sao Paulo, Brazil

C. J. D. G. Barbosa

Hospital do Coracao do Brasil, Distrito Federal, Brasília, Brazil

R. P. Giugliano

TIMI Study Group, Cardiovascular Division,

Department of Medicine, Brigham and Women's

Hospital and Harvard Medical School, Boston, MA, USA platelet reactivity in primary and secondary prevention.

Methods: $\operatorname{Lp}(a)$ was evaluated in 396 individuals with $(82.3 \%)$ and without (17.7\%) obstructive CAD. The population was divided into two groups according to $\operatorname{Lp}(a)$ concentrations with a cutoff value of $50 \mathrm{mg} / \mathrm{dL}$. The primary objective was to evaluate the association between $\mathrm{Lp}(a)$ and adenosine diphosphate (ADP)-

\section{S. G. Goodman}

Terrence Donnelly Heart Centre, St. Michael's Hospital, University of Toronto, Toronto, Canada

\section{P. A. Gurbel}

Sinai Center for Thrombosis Research and Drug Development, Sinai Hospital of Baltimore, Baltimore, MD, USA

R. C. Maranhão

Faculty of Pharmaceutical Science, University of Sao Paulo, Sao Paulo, Brazil

\section{R. C. Maranhão}

Lipid Metabolism Laboratory, Heart Institute (InCor) of the Medical School Hospital, University of Sao Paulo, São Paulo, Brazil 
induced platelet reactivity using the VerifyNow $^{\mathrm{TM}} \mathrm{P}_{2} \mathrm{Y}_{12}$ assay. Platelet reactivity was also induced by arachidonic acid and collagen-epinephrine (C-EPI) and assessed by Multiplate $^{\mathrm{TM}}$, platelet function analyzer ${ }^{\mathrm{TM}} 100$ (PFA-100), and light transmission aggregometry (LTA) assays. Secondary objectives included the assessment of the primary endpoint in individuals with or without CAD.

Results: Overall, 294 (74.2\%) individuals had $\mathrm{Lp}(a)<50 \mathrm{mg} / \mathrm{dL}$ [median (IQR) 13.2 (5.8-27.9) $\mathrm{mg} / \mathrm{dL}]$ and $102(25.8 \%)$ had $\mathrm{Lp}(a) \geq 50 \mathrm{mg} / \mathrm{dL}$ [82.5 (67.6-114.5) mg/dL], $P<0.001$. Univariate analysis in the entire population revealed no differences in ADP-induced platelet reactivity between individuals with $\operatorname{Lp}(a) \geq 50 \mathrm{mg} / \mathrm{dL}$ $(249.4 \pm 43.8 \mathrm{PRU})$ versus $\operatorname{Lp}(a)<50 \mathrm{mg} / \mathrm{dL}$ (243.1 $\pm 52.2 \mathrm{PRU}), P=0.277$. Similar findings were present in individuals with $(P=0.228)$ and without $(P=0.669) \mathrm{CAD}$, and regardless of the agonist used or method of analysis (all $P>0.05)$. Finally, multivariable analysis did not show a significant association between ADP-induced platelet reactivity and $\operatorname{Lp}(a) \geq 50 \mathrm{mg} / \mathrm{dL}$ [adjusted $\mathrm{OR}=1.00 \quad[(95 \%$ CI $\quad 0.99-1.01)$, $P=0.590]$.

Conclusion: In individuals with or without CAD, $\operatorname{Lp}(a) \geq 50 \mathrm{mg} / \mathrm{dL}$ was not associated with higher platelet reactivity.

Keywords: Coronary artery disease; Lipoprotein $(a)$; Platelet reactivity; Primary prevention

\section{Key Summary Points}

Why carry out this study?

High $\operatorname{Lp}(a)$ have been identified as an independent risk factor for coronary artery disease (CAD).

$\mathrm{Lp}(a)$ binds to platelets and ADP-P2 $\mathrm{Y}_{12}$ induced platelet reactivity is one of the main pathways involved in the occurrence of ischemic events in individuals with CAD.

To the best of our knowledge, there are no studies addressing the association between the concentrations of $\operatorname{Lp}(a)$ and platelet reactivity in individuals on primary or secondary prevention of cardiovascular disease.

\section{What was learned from the study?}

$\mathrm{Lp}(a) \geq 50 \mathrm{mg} / \mathrm{dL}$ was not associated with higher ADP-induced platelet reactivity measured by VerifyNow ${ }^{\mathrm{TM}} \mathrm{P}_{2} \mathrm{Y}_{12}$ point-ofcare assay in individuals regardless of the presence or absence of CAD.

This study suggests that platelet reactivity probably is not involved in the pathophysiological mechanisms underlying the atherothrombotic potential of $\operatorname{Lp}(a)$.

\section{DIGITAL FEATURES}

This article is published with digital features to facilitate understanding of the article. You can access the digital features on the article's associated Figshare page. To view digital features for this article go to https://doi.org/10.6084/m9. figshare. 12815906

\section{INTRODUCTION}

Lipoprotein (a) $[\operatorname{Lp}(a)]$ is synthesized by the liver and resembles the structure of low density 
lipoprotein cholesterol (LDL-C). However, $\operatorname{Lp}(a)$ also contains an additional protein, apolipoprotein $(a)[\operatorname{apo}(a)]$, that is bound to apolipoprotein B-100 by a single disulfide bond [1]. The blood concentration of $\operatorname{Lp}(a)$ in humans varies widely between individuals, from the near absence to several hundred milligrams per deciliter. It is now well established that high concentrations of $\operatorname{Lp}(a)$ are an independent factor for coronary artery disease (CAD) $[2,3]$.

Individuals with prior myocardial infarction (MI) have higher $\operatorname{Lp}(a)$ concentrations than healthy individuals, suggesting that $\operatorname{Lp}(a)$ might be causally associated with atherothrombosis $[4,5]$. Meta-analysis of 18 prospective studies that included 4040 cases of nonfatal MI or CAD deaths during a mean follow-up of 10 years estimated that individuals in the fourth versus third quartile of the $\operatorname{Lp}(a)$ concentration had a risk ratio of 1.7 [6]. The European Atherosclerosis Society Consensus Panel suggested $50 \mathrm{mg} /$ $\mathrm{dL}$ of $\operatorname{Lp}(a)$ as cutoff value for heightened risk for coronary events [7]. After 36 months mean follow-up period, stable outpatients with symptomatic CAD and $\operatorname{Lp}(a) \geq 50 \mathrm{mg} / \mathrm{dL}$ had a significantly higher risk of subsequent MI relative to those with $\operatorname{Lp}(a)<30 \mathrm{mg} / \mathrm{dL}$ [8]. A subanalysis from the FOURIER study of more than 25,000 patients with established atherosclerotic cardiovascular disease treated with moderate- or high-intensity statin and randomized to evolocumab or placebo showed a $22 \%$ higher risk of major coronary events (coronary death, MI, or urgent revascularization) among patients in the fourth versus first quartile of $\operatorname{Lp}(a)$ distribution [9]. However, in two other observational secondary prevention studies, the existence of the association between high $\operatorname{Lp}(a)$ and risk of recurrent coronary events was not evident $[10,11]$.

Various mechanisms by which high concentrations of $\operatorname{Lp}(a)$ could predispose to atherogenesis and atherothrombotic events have been proposed, including $\operatorname{Lp}(a)$ oxidation and direct deposition of this lipoprotein in the arterial wall, inhibition of fibrinolysis related to the homology of apo(a) with plasminogen, and induction of endothelial dysfunction and pathologic vascular reactivity [12-14].
The fact that some lipoproteins such as very low density lipoprotein (VLDL) and high density lipoprotein cholesterol (HDL-C) have effects on platelet reactivity, and the observation that $\mathrm{Lp}(a)$ binds to plasminogen receptors on the platelet surface through apo(a), led some investigators to explore the effects of $\operatorname{Lp}(a)$ on platelet function $[15,16]$. The results of in vitro studies are somewhat conflicting, suggesting that platelet reactivity may be either elevated, decreased, or unaffected by $\operatorname{Lp}(a)$ concentration [17-19]. Data are scarce regarding the relationship between $\operatorname{Lp}(a)$ concentrations and platelet reactivity in individuals in the presence versus absence of CAD [20]. Currently, despite the routine use of proven therapies, including antiplatelet drugs, individuals with CAD still have a significantly high risk of recurrent cardiovascular events [21], and it is important to unravel hidden factors that may account for this residual risk. Our main hypothesis was that platelet reactivity involving the adenosine diphosphate (ADP)-P2 $\mathrm{Y}_{12}$ pathway, which has strong relation to ischemic events [22], would be independently associated with higher concentrations of $\operatorname{Lp}(a)$. In this setting, this study aimed to investigate whether high $\operatorname{Lp}(a)$ concentration, defined as $\mathrm{Lp}(a) \geq 50 \mathrm{mg} / \mathrm{dL}$, is associated with platelet reactivity in individuals with and without CAD.

\section{METHODS}

\section{Study Population}

We performed a retrospective, cross-sectional study in 396 stable individuals from the ANTiplatelet Study (ANTs) group (NCT01896557, NCT03039205, NCT02316119, NCT03632785) who had baseline measurements of $\operatorname{Lp}(a)$ and platelet reactivity. Individuals were selected for this analysis if they fulfilled either of the following criteria: (1) Stable CAD defined as previous MI and/or at least 50\% coronary obstruction confirmed by coronary angiography and on non-enteric coated aspirin once daily for at least 1 month prior to enrollment; or (2) absence of obstructive CAD confirmed by multi-detector coronary computed tomography angiography (CTA), and not taking any antithrombotic therapy prior to 
enrollment. Key exclusion criteria were MI within the last 12 months, use of any antiplatelet therapy other than aspirin, history of hemorrhagic stroke, use of an oral anticoagulant, platelet count $<100,000$ or $>500,000 / \mu \mathrm{L}$, known liver disease, or coagulation disorder. The protocols for this research were approved by the Ethics Committee of the Clinical Hospitals, University of Sao Paulo Medical School [Approval Numbers: Comissão de Ética para Análise de Projetos de Pesquisa (CAPPesq) do Hospital das Clinicas da Faculdade de Medicina da Universidade de São Paulo (HCFMUSP): 0136-11 (NCT01896557); Certificado de Apresentação para Apreciação Ética (CAAE): 05965412.0.0000.0068 (NCT02316119); CAAE: 35079514.8.0000.0068 (NCT03039205, NCT03632785)]. The study was performed in accordance with the declaration of Helsinki 1964 and its later amendments. All participants provided written informed consent to participate in the study.

\section{Study Design}

Individuals were categorized into two groups according to $\operatorname{Lp}(a)$ concentrations above or below $50 \mathrm{mg} / \mathrm{dL}$. This cutoff was based on the current recommendations of the European Atherosclerosis Society [7, 23], American College of Cardiology/American Heart Association (ACC/AHA) [24, 25], and National Lipid Association [26]. Additionally, we used $\operatorname{Lp}(a)$ quartiles and $\operatorname{Lp}(a)$ with a threshold of $70 \mathrm{mg} / \mathrm{dL}$ to further evaluate the primary endpoint of this study.

\section{Lipoprotein $(a)$}

$\mathrm{Lp}(a)(\mathrm{mg} / \mathrm{dL})$ concentrations were measured in 241 (60.9\%) fresh and 155 (39.1\%) frozen serum samples by means of particle-enhanced immunonephelometry with N Latex $\mathrm{Lp}(a)$ Reagent, which is an $\operatorname{apo}(a)$ isoform-dependent assay (BN-II-System, Siemens HD) [27]. Serum samples were obtained the morning after overnight fasting by puncture of the antecubital vein and collected in tubes without an anticoagulant [CAT Serum Sep Clot Activator (Greiner Bio-One, Kremsmünster, Austria)]. Blood specimens were centrifuged at $3000 \mathrm{rpm}$ for $10 \mathrm{~min}$
(Eppendorf, Hamburg, Germany). The detection limit was approximately $0.2 \mathrm{mg} / \mathrm{dL}$. The intrarun coefficient of variation (CV) was $1.8-4.1 \%$ and inter-run $\mathrm{CV}$ was $2.8-5.3 \%$. The frozen samples (155 individuals) were stored at $-80^{\circ} \mathrm{C}$ immediately after collection and analyzed as a single batch to eliminate any source of error from inter-assay variability.

\section{Measurements of Platelet Reactivity}

Blood samples for platelet reactivity were drawn with a 21-gauge needle from the antecubital vein into blood-collecting tubes. After the first 2-3 mL of free-flowing blood was discarded, the tubes were filled to capacity and gently inverted three to five times to ensure complete mixing of the anticoagulant. Tubes containing 3.2\% sodium citrate were collected for VerifyNow ${ }^{\mathrm{TM}}$ measurements, tubes containing $3.2 \%$ trisodium citrate were used for light transmission aggregometry (LTA) and the platelet function analyzer (PFA)-100 assay (Greiner Bio-One, Kremsmünster, Austria), while double wall Hirudin Blood Tubes were used for the Multiplate $^{\mathrm{TM}}$ assay (Roche Diagnostics, Rotkreuz, Switzerland). Platelet reactivity tests were performed within $2 \mathrm{~h}$ after sample collection.

(a) VerifyNow ${ }^{\mathrm{TM}}$ assay. Platelet reactivity induced by ADP (VerifyNow ${ }^{\mathrm{TM}} \mathrm{P}^{2} \mathrm{Y}_{12}$ ) (primary objective) or arachidonic acid (VerifyNow $^{\mathrm{TM}}$ Aspirin) was assessed in whole blood with the VerifyNow ${ }^{\mathrm{TM}}$ point-of-care assay (Accriva Diagnostics, San Diego, California, USA) as previously was described [28]. In brief, VerifyNow is a turbidimetrybased optical detection assay designed to measure platelet agglutination that is based on the ability of activated platelets to bind to fibrinogen. The cartridge contains a lyophilized preparation of human fibrinogen-coated beads, ADP or arachidonic acid, preservative, and buffer. The fibrinogencoated beads aggregate in whole blood in proportion to the number of unblocked platelet GPIIb/IIIa receptors. The instrument reported platelet reactivity as $\mathrm{P}_{2} \mathrm{Y}_{12}$ reaction units (PRU) or aspirin reaction units (ARU), as appropriate. 
(b) PFA-100 assay. In the PFA-100 assay (Siemens Healthcare Diagnostics, Newark, Delaware, USA), platelets are exposed to high shear conditions within a cartridge containing a capillary, a sample reservoir, a collagen and epinephrine (C-EPI)-coated membrane, and an aperture [29]. C-EPI activates platelets in whole blood, creating aggregate formation at the aperture, gradually diminishing and finally arresting blood flow. The PFA-100 records the time in seconds from the start of the test until the platelet aggregate occludes the aperture (closure time).

(c) Multiplate $\mathrm{T}^{\mathrm{TM}}$ assay. The Multiplate ${ }^{\mathrm{TM}}$ analyzer (Roche Diagnostics, Rotkreuz, Switzerland) is a multiple electrode impedance aggregometer and point-of-care assay that assesses platelet reactivity in whole blood as previously described $[28,30]$. Briefly, whole blood was added to the test cuvettes, diluted (1:2 with $0.9 \%$ $\mathrm{NaCl}$ solution), stirred, and warmed to $37^{\circ} \mathrm{C}$. ADP or arachidonic acid was added to a final concentration of $6.5 \mu \mathrm{mol} / \mathrm{L}$ (ADP test) or $0.5 \mathrm{mmol} / \mathrm{L}$ (ASPI test), as appropriate. Reactivity was then continuously recorded for $6 \mathrm{~min}(\mathrm{~min})$. Test results were quantified as area under the curve (AU) and expressed as aggregation units per min (AU min).

(d) LTA. Platelet aggregation was assessed as described previously [31]. In brief, the blood-citrate tubes were centrifuged at $1000 \mathrm{rpm}$ for $10 \mathrm{~min}$ to recover plateletrich plasma (PRP) and further centrifuged at $3000 \mathrm{rpm}$ for $10 \mathrm{~min}$ to recover plateletpoor plasma (PPP). PRP and PPP were stored at room temperature to be used within $30 \mathrm{~min}$. Platelets were stimulated with $5 \mu \mathrm{mol} / \mathrm{L}$ ADP. Aggregation was assessed using an AggRAM ${ }^{\mathrm{TM}}$ aggregometer (Helena Laboratories Corp., Beaumont, TX) and expressed as the maximum percent change in light transmittance from baseline, using PPP as reference.

(e) Thromboxane $\mathrm{B}_{2}\left(\mathrm{TxB}_{2}\right)$. $\mathrm{TxB}_{2}(\mathrm{pg} / \mathrm{mL})$ was measured in serum samples using a commercial ELISA kit (Millipore Sigma; Burlington, MA, USA), as previously described
[32]. Briefly, PRP treated with $10 \mu \mathrm{mol} / \mathrm{L}$ ADP was quenched for 5 min with $5 \mathrm{mmol} /$ $\mathrm{L}$ ethylenediaminetetraacetic acid and $200 \mu \mathrm{mol} / \mathrm{L}$ indomethacin. The samples were centrifuged for $10 \mathrm{~min}$ at $3000 \mathrm{rpm}$. The supernatant was removed and stored at $-80^{\circ} \mathrm{C}$ for subsequent $\mathrm{TxB}_{2}$ analysis using a Multiskan FC plate reader (Thermo Fisher Scientific, Waltham, MA, USA).

\section{Statistical Analysis}

Categorical variables were expressed as absolute numbers and percentages and were compared with the chi-square test. Continuous variables were described as mean \pm standard deviation (SD) or median (IQR, interquartile range: 25th-75th percentiles) and the Student's $t$ test (normal distribution) or Mann-Whitney test (non-Gaussian distribution) was applied, as appropriate. The Shapiro-Wilk test was used for normality evaluation. The Spearman rank correlation test was utilized to compare the univariate association between $\mathrm{Lp}(a)$ concentrations and ADP-induced platelet reactivity evaluated by VerifyNow ${ }^{\mathrm{TM}} \mathrm{P}_{2} \mathrm{Y}_{12}$, both as continuous variables.

In order to assess the independent association between dichotomized $\operatorname{Lp}(a)(<50 \mathrm{mg} / \mathrm{dL}$ versus $\geq 50 \mathrm{mg} / \mathrm{dL}$ ) and ADP-induced platelet reactivity, a stepwise logistic regression model was constructed. Categories of $\operatorname{Lp}(a)$ concentrations (as dependent variable) were adjusted for the following candidate independent variables: age; sex; non-Caucasian or non-Asian; height; weight; history of hypertension; diabetes; dyslipidemia; previous MI; previous stroke; current smoker; hemoglobin; platelet count; glycated hemoglobin (HbA1c); creatinine; total cholesterol (TC); HDL-C; LDL-C; triglycerides (TG); chronic statin use, angiotensin-converting enzyme inhibitor (ACEI)/angiotensin receptor blockers (ARB); $\beta$-blockers; oral anti-hyperglycemic drugs or insulin; and ADP-induced platelet reactivity. Cutoff $P$ values of 0.05 for inclusion and 0.10 for exclusion at each step were used to fit the model. Similarly, a multivariable linear regression model was used to evaluate the independent association between 
ADP-induced platelet reactivity and $\operatorname{Lp}(a)$, both as continuous variables. The independent covariates used were the same as those for the adjusted stepwise logistic regression model. ADP-induced platelet reactivity by VerifyNow ${ }^{\mathrm{TM}}$ $\mathrm{P}_{2} \mathrm{Y}_{12}$ was determined by $\operatorname{Lp}(a)$ quartile and compared across those by Kruskal-Wallis test. The median test for $k$ samples was applied for the comparison between median $\operatorname{Lp}(a)$ concentrations in frozen or fresh serum samples.

We have also run additional sensitivity analyses (1) excluding variables that could have potential collinearity with other variables in the same model; and (2) including all variables in the model, without variables selection by stepwise procedure. The Hosmer-Lemeshow test was used to assess the goodness of fit of the main model.

Since we had 396 individuals with samples available for both $\operatorname{Lp}(a)$ and ADP-induced platelet reactivity, we performed a post-hoc power calculation assessing the difference in platelet reactivity that could be detected in individuals with $\mathrm{Lp}(a) \geq 50 \mathrm{mg} / \mathrm{dL}$ versus $<50 \mathrm{mg} / \mathrm{dL}$. On the basis of a prior study from our group [33], individuals with CAD on aspirin had a mean reactivity of $251.74 \pm 43.72 \mathrm{PRU}$. For a twotailed $\alpha$ equal to 0.05 , the study had $80 \%$ power to detect a mean difference of 12.4 PRU and $90 \%$ power to detect a mean difference of 14.4 PRU between both groups of interest (Supplementary Table 5).

All tests were two-tailed and value of $P<0.05$ was considered statistically significant. Data were analyzed using IBM SPSS Statistics 26.0 (Microsoft, Chicago, IL, USA) and Stata ${ }^{\mathrm{TM}}$ version 15.1 (Statacorp, College Station, TX, USA).

\section{RESULTS}

\section{Distribution of $\operatorname{Lp}(a)$ Concentrations}

The distribution of $\operatorname{Lp}(a)(\mathrm{mg} / \mathrm{dL})$ was highly skewed with a marked left shift (Fig. 1). The median $\operatorname{Lp}(a)$ concentration in the population $(N=396)$ was $22.0(7.9-52.2) \mathrm{mg} / \mathrm{dL}$ (Table 1$)$. No individuals had an $\operatorname{Lp}(a)$ concentrations below the limit of detectability $(0.2 \mathrm{mg} / \mathrm{dL})$. The median concentrations for fresh vs frozen serum samples were $27.8(10.4-67.4) \mathrm{mg} / \mathrm{dL}$ versus $15.7(6.1-37.6) \mathrm{mg} / \mathrm{dL}(P<0.0001)$.

\section{Study Groups}

The baseline characteristics of the study population are shown in Table 1 . The median age was $66(61-72)$ years and $266(67.2 \%)$ were male.

Of the 396 individuals included in this study, $294(74.2 \%)$ had $\operatorname{Lp}(a)<50 \mathrm{mg} / \mathrm{dL}$ and 102 (25.8\%) had $\operatorname{Lp}(a) \geq 50 \mathrm{mg} / \mathrm{dL}$. The median concentrations observed in each group were $13.2(5.8-27.9) \mathrm{mg} / \mathrm{dL}$ and 82.5 (67.6-114.5) $\mathrm{mg} / \mathrm{dL}$, respectively.

Significant differences were observed between patients with higher versus lower $\operatorname{Lp}(a)$. Among individuals with $\operatorname{Lp}(a) \geq 50 \mathrm{mg} /$ $\mathrm{dL}$, a greater percentage of individuals were neither Caucasian nor Asian $(P=0.001)$, had previous coronary artery bypass graft (CABG) surgery $(P=0.009)$, and had a prior stroke $(P=0.003)$, compared to those with $\mathrm{Lp}(a)<50 \mathrm{mg} / \mathrm{dL}$. Conversely, individuals with elevated $\operatorname{Lp}(a)$ were less likely to have diabetes $(P=0.048)$, smoke $(P=0.029)$, lower weight $(P=0.003)$, or lower body mass index (BMI) $(P=0.006)$. Regarding laboratory findings, individuals with $\operatorname{Lp}(a) \geq 50 \mathrm{mg} / \mathrm{dL}$ exhibited lower fasting glucose $(P=0.045)$ and triglycerides $(P=0.013)$ levels, and a trend toward higher HDL-C levels $(P=0.050)$. Individuals with $\operatorname{Lp}(a) \geq 50 \mathrm{mg} / \mathrm{dL}$ also were more frequently receiving statin $(P=0.014)$ and aspirin $(P=0.016)$. On the other hand, the groups stratified by $\operatorname{Lp}(a)$ were well balanced regarding age, sex, height, history of hypertension and dyslipidemia, previous MI or percutaneous coronary intervention (PCI). Additionally, no significant differences between the groups were found with respect to the rest of the laboratory parameters analyzed or medications.

The baseline characteristics from individuals in the presence and absence of CAD are shown in Table 2. Individuals with CAD had higher median $\operatorname{Lp}(a)$ concentrations compared to those without CAD $23.2(8.1-59.4) \mathrm{mg} / \mathrm{dL}$ versus 14.9 (6.9-34.4) $\mathrm{mg} / \mathrm{dL},(P=0.021)$. 


\section{Association Between $\operatorname{Lp}(a)$ Concentrations and Platelet Reactivity}

ADP-induced platelet reactivity by VerifyNow ${ }^{\mathrm{TM}}$ $\mathrm{P}_{2} \mathrm{Y}_{12}$ assay: No significant differences were found in ADP-induced platelet reactivity between the individuals with $\operatorname{Lp}(a) \geq 50 \mathrm{mg} / \mathrm{dL}$ when compared to those with $\operatorname{Lp}(a)<50 \mathrm{mg} / \mathrm{dL}$ $(249.4 \pm 43.8 \mathrm{PRU}$ versus $243.1 \pm 52.2 \mathrm{PRU}$, respectively, $P=0.277$ ) (Fig. 2 a). Similarly, no association was observed in ADP-mediated platelet reactivity between individuals with $\mathrm{Lp}(a)<50 \mathrm{mg} / \mathrm{dL}$ versus $\operatorname{Lp}(a) \geq 50 \mathrm{mg} / \mathrm{dL}$ who had CAD $(250.2 \pm 45.5$ PRU versus $242.2 \pm$ 56.3 PRU, respectively, $P=0.228$ ) (Fig. $2 b$ ) or among those without CAD $(242.0 \pm 23.1$ PRU versus $246.5 \pm 31.4 \mathrm{PRU}$, respectively, $P=0.669$ ) (Fig. 2c). In addition, no association was observed in ADP-induced platelet reactivity between individuals with $\operatorname{Lp}(a) \geq 50 \mathrm{mg} / \mathrm{dL}$ or $\mathrm{Lp}(a)<50 \mathrm{mg} / \mathrm{dL}$ whose measurements were made in fresh $(252.3 \pm 44.5$ PRU versus $251.6 \pm$ 46.0 PRU, respectively, $P=0.908$ ) or in frozen serum samples $(231.8 \pm 58.6$ PRU versus 241.9 \pm 35.1 PRU, respectively, $P=0.505$ ). Finally, there were no significant relationships in ADP-

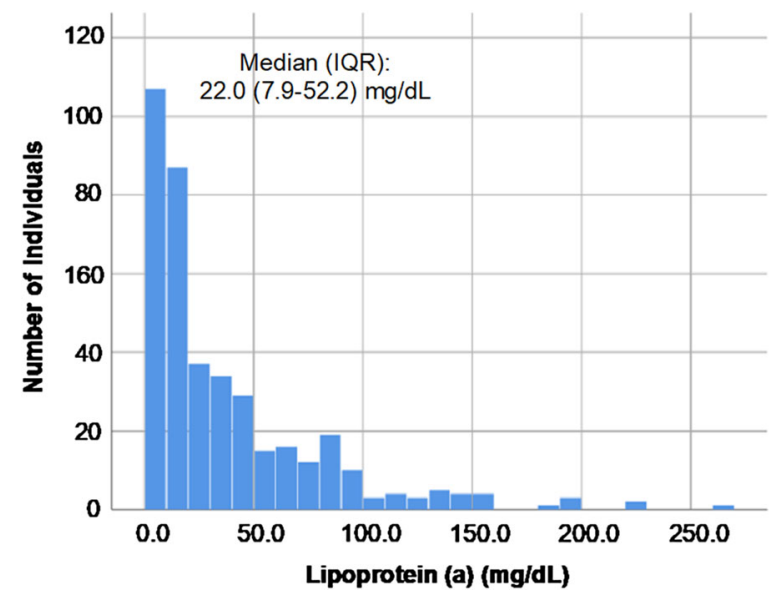

Fig. 1 Distribution of lipoprotein (a) concentrations. Serum $\operatorname{Lp}(a)$ concentrations in $\mathrm{mg} / \mathrm{dL}$ from $326(82.3 \%)$ individuals with CAD and $70(17.7 \%)$ individuals without CAD are shown in a frequency distribution histogram. Distribution are from Kolmogorov-Smirnov test (see “Methods"). Median (IQR) $=22.0 \quad(7.9-52.2) \mathrm{mg} / \mathrm{dL}$. $\mathrm{Lp}(a)$ lipoprotein $(a), \mathrm{CAD}$ coronary artery disease, IQR interquartile range induced platelet reactivity across $\operatorname{Lp}(a)$ quartiles: Q1 [<7.9 mg/dL; 245.0 (215.0-274) PRU]; Q2 [7.9-22.0 mg/dL; 240.0 (212.0-271.0) PRU]; Q3 [22.1-51.5 mg/dL; 254.0 (215.0-280.0]; and Q4 [> 51.5 mg/dL; 248.0 (220.0-270.0) PRU], $P=0.365$ (Supplementary Fig. 1); nor between individuals with $\operatorname{Lp}(a)$ values $\geq 70 \mathrm{mg} / \mathrm{dL}$ when compared to those with $\operatorname{Lp}(a)<70 \mathrm{mg} / \mathrm{dL}$ [250.5 (219.2-281.0) PRU versus 247.0 (215.0-272.5) PRU, respectively, $\quad P=0.491]$ (Supplementary Fig. 2).

Results of platelet reactivity using different agonists by PFA-100 (E-EPI), VerifyNow ${ }^{\mathrm{TM}}$ Aspirin, Multiplate $^{\mathrm{TM}}$ ADP, Multiplate ${ }^{\mathrm{TM}}$ ASPI, and LTA (ADP) assays: As can be seen in Table 3, there were no significant differences between different agonists-induced platelet reactivity from individuals with concentrations of $\mathrm{Lp}(a) \geq 50 \mathrm{mg} / \mathrm{dL}$ compared to those with $\mathrm{Lp}(a)<50 \mathrm{mg} / \mathrm{dL}$, when platelet reactivity was assessed by any of these tests: 117 (97.0-165.5) versus $102.0(86.0-145.0) \mathrm{s}(P=0.235)$ for the PFA-100 with C-EPI; $527.4 \pm 83.7$ versus 530.0 \pm 80.4 ARU $(P=0.819)$ for the VerifyNow ${ }^{\mathrm{TM}}$ Aspirin; $73.3 \pm 21.3$ versus $73.2 \pm 23.4 \mathrm{AU}$ min $(P=0.996)$ for the Multiplate ${ }^{\mathrm{TM}}$ ADP; $76.1 \pm$ 26.9 versus $71.4 \pm 24.3 \mathrm{AU} \min (P=0.532)$ for the Multiplate ${ }^{\mathrm{TM}}$ ASPI; and 75.1 (70.5-82.8) versus $80.6(74.1-84.5) \%(P=0.112)$ for the LTA (ADP).

Serum $\mathrm{TxB}_{2}$ measurement: No differences in $\mathrm{TxB}_{2}$ levels were found between individuals with $\operatorname{Lp}(a)<50 \mathrm{mg} / \mathrm{dL}$ or $\operatorname{Lp}(a) \geq 50 \mathrm{mg} / \mathrm{dL}$ in a subgroup $(n=59)$ where this test was available (Table 3).

In the adjusted logistic regression model, $\mathrm{Lp}(a) \geq 50 \mathrm{mg} / \mathrm{dL}$ was not independently associated with ADP-induced platelet reactivity assessed by VerifyNow ${ }^{\mathrm{TM}} \mathrm{P}_{2} \mathrm{Y}_{12}$ assay [odds ratio $(\mathrm{OR})=1.00 \quad[(95 \%$ CI $0.99-1.01), \quad P=0.590]$; Hosmer-Lemeshow chi-square was 514.27 $(P<0.0001)$. In this model, the variables significantly and independently associated with $\mathrm{Lp}(a) \geq 50 \mathrm{mg} / \mathrm{dL}$ were creatinine $[\mathrm{OR}=2.06$ (95\% CI $1.11-3.85)$ for every $\mathrm{mg} / \mathrm{dL}, P=0.023]$, LDL-C [OR 1.01 (95\% CI 1.00-1.02) for every $\mathrm{mg} / \mathrm{dL}, P=0.007$ ], prior stroke [OR 2.07 (95\% CI 1.12-3.82), $P=0.021]$, non-Caucasian or non-Asian [OR $2.78 \quad(95 \%$ CI $1.67-4.63)$, $P<0.001$ ], TG [OR 0.99 (95\% CI 0.98-0.99) for 
Table 1 Baseline characteristics of individuals according to $\operatorname{Lp}(a)$ concentrations

\begin{tabular}{|c|c|c|c|c|}
\hline & $\begin{array}{l}\text { Total } \\
(n=396)\end{array}$ & $\begin{array}{l}\mathrm{Lp}(a)<50 \mathrm{mg} / \mathrm{dL} \\
(n=294)\end{array}$ & $\begin{array}{l}\mathrm{Lp}(a) \geq 50 \mathrm{mg} / \mathrm{dL} \\
(n=102)\end{array}$ & $P$ value \\
\hline \multicolumn{5}{|l|}{ Clinical characteristics } \\
\hline Age, years [median (IQR)] & $66.0(61.0-72.0)$ & $66.0(61.0-71.2)$ & $66.5(60.7-73.0)$ & 0.687 \\
\hline Male sex $[n(\%)]$ & $266(67.2)$ & $204(69.4)$ & $62(60.8)$ & 0.111 \\
\hline $\begin{array}{l}\text { Non-Caucasian or non-Asian } \\
{[n(\%)]}\end{array}$ & $139(35.1)$ & $85(28.9)$ & $54(52.9)$ & $<0.001$ \\
\hline Height (m) [median (IQR)] & $1.65(1.59-1.71)$ & $1.65(1.59-1.71)$ & $1.63(1.58-1.72)$ & 0.241 \\
\hline Weight $(\mathrm{kg})[$ median (IQR)] & $75.0(66.5-83.9)$ & $76.0(68.0-84.1)$ & $72.0(62.0-80.0)$ & 0.003 \\
\hline BMI $\left(\mathrm{kg} / \mathrm{m}^{2}\right)$ [median (IQR)] & $27.4(24.8-30.4)$ & $27.8(25.2-30.8)$ & $26.5(23.9-29.0)$ & 0.006 \\
\hline History of hypertension $[n(\%)]$ & $323(81.6)$ & $234(79.6)$ & $89(87.3)$ & 0.085 \\
\hline History of diabetes $[n(\%)]$ & $161(40.7)$ & $128(43.5)$ & $33(32.4)$ & 0.048 \\
\hline History of dyslipidemia $[n(\%)]$ & $290(73.2)$ & $212(72.1)$ & $78(76.5)$ & 0.391 \\
\hline Previous MI $[n(\%)]$ & $269(67.9)$ & $198(67.3)$ & $71(69.6)$ & 0.673 \\
\hline Previous PCI $[n(\%)]$ & $207(52.3)$ & $155(52.7)$ & $52(51.0)$ & 0.762 \\
\hline Previous CABG $[n(\%)]$ & $98(24.7)$ & $63(21.4)$ & $35(34.3)$ & 0.009 \\
\hline Previous stoke $[n(\%)]$ & $64(16.2)$ & $38(12.9)$ & $26(25.5)$ & 0.003 \\
\hline Current smoker $[n(\%)]$ & $37(9.3)$ & $33(11.2)$ & $4(3.9)$ & 0.029 \\
\hline \multicolumn{5}{|l|}{ Laboratory findings } \\
\hline Hemoglobin $(\mathrm{g} / \mathrm{dL})[$ mean $(\mathrm{SD})]$ & $14.2 \pm 1.5$ & $14.2 \pm 1.4$ & $14.1 \pm 1.6$ & 0.397 \\
\hline $\begin{array}{l}\text { Platelets count }\left(10^{3} / \mu \mathrm{L}\right) \\
{[\text { median }(\mathrm{IQR})]}\end{array}$ & $219.0(185.0-261.0)$ & $215.5(183.0-262.0)$ & $224.0(195.7-254.5)$ & 0.255 \\
\hline WBC $\left(10^{3} / \mu \mathrm{L}\right)[$ median $(\mathrm{IQR})]$ & $7.2(6.0-8.5)$ & $7.2(6.0-8.5)$ & $7.1(5.6-8.2)$ & 0.115 \\
\hline$h s-\mathrm{CRP}(\mathrm{mg} / \mathrm{L})[\operatorname{median}(\mathrm{IQR})]$ & $1.6(0.6-3.9)$ & $1.6(0.6-3.8)$ & $1.7(0.7-5.6)$ & 0.459 \\
\hline $\begin{array}{l}\text { Fasting glucose }(\mathrm{mg} / \mathrm{dL}) \\
{[\text { median }(\mathrm{IQR})]}\end{array}$ & $105.0(96.0-121.0)$ & $106.0(96.7-124.0)$ & $102.5(95.0-117.7)$ & 0.045 \\
\hline HbAlc (\%) [median (IQR)] & $6.0(5.6-6.7)$ & $6.0(5.7-6.7)$ & $5.9(5.6-6.4)$ & 0.360 \\
\hline Creatinine $(\mathrm{mg} / \mathrm{dL})$ [median (IQR)] & $1.05(0.89-1.29)$ & $1.03(0.89-1.28)$ & $1.12(0.88-1.31)$ & 0.204 \\
\hline $\begin{array}{l}\operatorname{MDRD}\left(\mathrm{ml} / \mathrm{min} / 1.73 \mathrm{~m}^{2}\right) \\
{[\operatorname{median}(\mathrm{IQR})]}\end{array}$ & $71.2(54.9-85.9)$ & $71.7(56.3-87.2)$ & $66.6(49.9-83.2)$ & 0.054 \\
\hline $\mathrm{TC}(\mathrm{mg} / \mathrm{dL})[$ median $(\mathrm{IQR})]$ & $157.0(134.2-188.7)$ & $156.0(132.0-188.2)$ & $161.0(140.7-189.2)$ & 0.284 \\
\hline HDL-C (mg/dL) [median (IQR)] & $43(36-51)$ & $43(36-50)$ & $45(38-54)$ & 0.050 \\
\hline LDL-C (mg/dL) [median (IQR)] & $88.0(69.0-116.0)$ & $87.0(66.0-116.0)$ & $90.0(77.7-118.5)$ & 0.053 \\
\hline $\mathrm{TG}(\mathrm{mg} / \mathrm{dL})[\operatorname{median}(\mathrm{IQR})]$ & $115.0(81.0-161.0)$ & $119.5(85.0-170.0)$ & $105.5(75.0-138.2)$ & 0.013 \\
\hline $\mathrm{Lp}(a)(\mathrm{mg} / \mathrm{dL})[$ median $(\mathrm{IQR})]$ & $22.0(7.9-52.2)$ & $13.2(5.8-27.9)$ & $82.5(67.6-114.5)$ & $<0.001$ \\
\hline
\end{tabular}


Table 1 continued

\begin{tabular}{lllll}
\hline & $\begin{array}{l}\text { Total } \\
(\boldsymbol{n}=\mathbf{3 9 6})\end{array}$ & $\begin{array}{l}\mathbf{L p}(\boldsymbol{a})<\mathbf{5 0} \mathbf{~ m g} / \mathbf{d L} \\
(\boldsymbol{n}=\mathbf{2 9 4})\end{array}$ & $\begin{array}{l}\mathbf{L p}(\boldsymbol{a}) \geq \mathbf{5 0} \mathbf{~ m g} / \mathbf{d L} \\
(\boldsymbol{n}=\mathbf{1 0 2})\end{array}$ & $\boldsymbol{P}$ value \\
\hline $\begin{array}{l}\text { Medications }[n(\%)] \\
\text { Statin }\end{array}$ & $345(87.1)$ & $249(84.7)$ & $96(94.1)$ & 0.014 \\
Aspirin & $326(82.3)$ & $234(79.6)$ & $92(90.2)$ & 0.016 \\
ACEI/ARB & $299(75.5)$ & $219(74.5)$ & $80(78.4)$ & 0.425 \\
$\beta$-blocker & $333(84.1)$ & $250(85.0)$ & $83(81.4)$ & 0.384 \\
Anti-hyperglycemic drugs & & & & \\
$\quad$ Oral & $151(38.1)$ & $120(40.8)$ & $31(30.4)$ & 0.062 \\
$\quad$ Insulin & $47(11.9)$ & $40(13.6)$ & $7(11.9)$ & 0.070 \\
\hline
\end{tabular}

Values are expressed as mean $\pm \mathrm{SD}$, median (IQR), or number of individuals (\%)

$L p($ a) lipoprotein $(a), B M I$ body mass index, $M I$ myocardial infarction, $P C I$ percutaneous coronary intervention, $C A B G$ coronary artery bypass graft, $W B C$ white blood cells, $h s$-CRP high-sensitivity C-reactive protein, $H b A 1 c$ glycated hemoglobin, MDRD Modification of Diet in Renal Disease, $T C$ total cholesterol, $H D L-C$ high density lipoprotein cholesterol, $L D L-C$ low density lipoprotein cholesterol, $T G$ triglycerides, $A C E I$ angiotensin-converting enzyme inhibitor, $A R B$ angiotensin receptor blocker, $I Q R$ interquartile range

$P$ values are from Student's $t$ test, Mann-Whitney test, or chi-square test

every $\mathrm{mg} / \mathrm{dL}, P=0.011]$, and use of statins [OR 4.74 (95\% CI 1.69-13.33), $P=0.003$ ]. Similar results were found regarding the association of ADP-induced platelet reactivity with $\mathrm{Lp}(a) \geq 50 \mathrm{mg} / \mathrm{dL}$ using a multivariable regression model without a stepwise approach $(P=0.512)$ (Supplementary Table 2$)$, or when potentially collinear variables were excluded $(P=0.572)$ (Supplementary Table 3). In addition, ADP-induced platelet reactivity was not independently associated with $\operatorname{Lp}(a) \geq 50 \mathrm{mg}$ / $\mathrm{dL}(P=0.478)$ in a multivariable linear regression model which included only age, sex, race, LDL-C, and prior statin variables (Supplementary Table 4).

Furthermore, no associations were observed between $\operatorname{Lp}(a)$ concentrations and ADP-induced platelet reactivity assessed by VerifyNow ${ }^{\mathrm{TM}}$

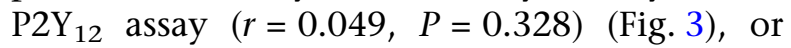
when the population was stratified by the presence $(r=0.063, P=0.254)$ or absence $(r=-0.034, P=0.781)$ of CAD. No associations were found when we analyzed either fresh $(r=0.029, \quad P=0.654)$ or frozen $(r=0.001$,
$P=0.985)$ serum samples separately. In the multivariable linear regression analysis, $\operatorname{Lp}(a)$ was not independently associated with ADP-induced platelet reactivity when both were assessed as continuous variables (adjusted beta coefficient $0.024 ; 95 \%$ confidence interval (CI) -0.077 to 0.124 ; adjusted $P=0.650$ ). This lack of association was observed regardless of the presence or absence of CAD (adjusted beta coefficient 0.036 ; $95 \%$ CI -0.077 to 0.148 ; adjusted $P=0.530$ for individuals with CAD; adjusted beta coefficient $-0.120 ; 95 \%$ CI -0.296 to 0.056 ; adjusted $P=0.180$ for individuals without $C A D ; P$ for interaction $=0.670$ ).

For the primary outcome, we performed post hoc power calculations, assuming clinically meaningful differences that could have been detected between the groups of interest. Namely, our study preserved a power of $96.8 \%$ to detect a difference of $20 \mathrm{PRU}$ and a power of $99.9 \%$ to detect a difference of 30 PRU in the platelet reactivity between individuals with $\mathrm{Lp}(a) \geq 50 \mathrm{mg} / \mathrm{dL}$ versus $\operatorname{Lp}(a)<50 \mathrm{mg} / \mathrm{dL}$ (Supplementary Table 5). 
Table 2 Baseline characteristics of individuals with and without CAD

With CAD

$(n=326)$

Clinical characteristics

Age, years [median (IQR)]

Male sex $[n(\%)]$

Non-Caucasian or non-Asian [ $n(\%)]$

Height (m) [median (IQR)]

Weight $(\mathrm{kg})$ [median (IQR)]

BMI $\left(\mathrm{kg} / \mathrm{m}^{2}\right)$ [median (IQR)]

History of hypertension $[n(\%)]$

History of diabetes [n (\%)]

History of dyslipidemia [ $n(\%)]$

Prior MI $[n(\%)]$

Prior PCI $[n(\%)]$

Prior CABG $[n(\%)]$

Prior stoke $[n(\%)]$

Current smoker $[n(\%)]$

Laboratory findings

Hemoglobin $(\mathrm{g} / \mathrm{dL})$ [mean (SD)]

Platelets count $\left(10^{3} / \mu \mathrm{L}\right)$ [median (IQR)]

WBC $\left(10^{3} / \mu \mathrm{L}\right)$ [median (IQR)]

hs-CRP (mg/L) [median (IQR)]

Fasting glucose $(\mathrm{mg} / \mathrm{dL})$ [median (IQR)]

HbAlc (\%) [median (IQR)]

Creatinine $(\mathrm{mg} / \mathrm{dL})$ [median (IQR)]

$\operatorname{MDRD}\left(\mathrm{ml} / \mathrm{min} / 1.73 \mathrm{~m}^{2}\right)$ [mean (SD)]

TC $(\mathrm{mg} / \mathrm{dL})$ [median $(\mathrm{IQR})]$

HDL-C (mg/dL) [median (IQR)]

LDL-C (mg/dL) [median (IQR)]

TG (mg/dL) [median (IQR)]

$\mathrm{Lp}(a)(\mathrm{mg} / \mathrm{dL})$ [median (IQR)]

Medications $[n(\%)]$

Statin

Aspirin

$326(100.0)$

$68.0(62.0-73.0)$
$233(71.5)$
$130(39.9)$
$1.65(1.59-1.71)$
$74.7(66.5-83.1)$
$27.4(24.8-30.3)$
$279(85.6)$
$150(46.0)$
$248(76.1)$
$269(82.5)$
$207(63.5)$
$98(30.1)$
$64(19.6)$
$33(10.1)$

$14.3 \pm 1.5$

$219.0(185.0-266.5)$

$7.4(6.1-8.5)$

$1.6(0.6-4.3)$

$107.0(98.0-125.7)$

$6.1(5.7-6.9)$

$1.1(0.9-1.3)$

$68.1 \pm 22.0$

152.0 (132.0-181.0)

$42(36-50)$

$85.0(66.0-107.2)$

$115.5(81.0-170.0)$

$23.2(8.1-59.4)$
Without CAD

$(n=70)$

$\begin{array}{lr}60.5(54.0-65.0) & <0.001 \\ 33(47.1) & <0.001 \\ 9(12.9) & <0.001 \\ 1.65(1.58-1.73) & 0.910 \\ 75.0(68.5-86.2) & 0.537 \\ 27.8(25.3-30.6) & 0.381 \\ 44(62.9) & <0.001 \\ 11(15.7) & <0.001 \\ 42(60.0) & 0.006 \\ 0(0.0) & \text { N/A } \\ 0(0.0) & \text { N/A } \\ 0(0.0) & \text { N/A } \\ 0(0.0) & \text { N/A } \\ 4(5.7) & 0.250\end{array}$

$13.6 \pm 1.0$

$<0.001$

$219.5(184.5-252.0)$

0.455

$6.2(5.2-7.5)$

$<0.001$

$1.7(0.7-3.6)$

0.854

$98.0(90.0-105.0)$

$<0.001$

$5.6(5.4-6.0)$

$<0.001$

$0.9(0.7-1.0)$

$<0.001$

$82.6 \pm 19.0$

$<0.001$

185.0 (155.7-211.7)

$<0.001$

$46(40-56)$

0.001

$113.0(88.7-133.2)$

$<0.001$

$109.5(83.5-130.2)$

0.046

14.9 (6.9-34.4)

0.021

36 (51.4)

$<0.001$

$\mathrm{N} / \mathrm{A}$ 
Table 2 continued

\begin{tabular}{lllr}
\hline & $\begin{array}{l}\text { With CAD } \\
(\boldsymbol{n}=\mathbf{3 2 6})\end{array}$ & $\begin{array}{l}\text { Without CAD } \\
(\boldsymbol{n}=\mathbf{7 0})\end{array}$ & $\boldsymbol{P}$ value \\
\hline ACEI/ARB & $256(78.5)$ & $43(61.4)$ & 0.003 \\
$\beta$-blocker & $292(89.6)$ & $41(58.6)$ & $<0.001$ \\
Anti-hyperglycemic drugs & & & \\
Oral & $143(43.9)$ & $8(11.4)$ & 0.001 \\
Insulin & $46(14.1)$ & $1(1.4)$ & 0.003 \\
\hline
\end{tabular}

Values are expressed as mean $\pm \mathrm{SD}$, median (IQR), or number of individuals (\%)

$C A D$ coronary artery disease, $B M I$ body mass index, $M I$ myocardial infarction, $P C I$ percutaneous coronary intervention, $C A B G$ coronary artery bypass graft, $W B C$ white blood cells, $b s-C R P$ high-sensitivity C-reactive protein, $H b A l c$ glycated hemoglobin, MDRD Modification of Diet in Renal Disease, $T C$ total cholesterol, $H D L-C$ high density lipoprotein cholesterol, $L D L-C$ low density lipoprotein cholesterol, $T G$ triglycerides, $L p(a)$ lipoprotein (a), $A C E I$ angiotensin-converting enzyme inhibitor, $A R B$ angiotensin receptor blocker, $I Q R$ interquartile range, $N / A$ not applicable

$P$ values are from Student's $t$ test, Mann-Whitney test, or chi-square test

\section{DISCUSSION}

Our main finding was that high $\operatorname{Lp}(a)$ concentration, defined as $\mathrm{Lp}(a) \geq 50 \mathrm{mg} / \mathrm{dL}$ $[23-26,34]$, is unrelated to platelet reactivity as assessed by multiple established tests [31-36], and regardless of the presence or absence of CAD. To the best of our knowledge, the present study is the first to analyze the potential association between high concentrations of $\mathrm{Lp}(a)$ and platelet reactivity in individuals with and without $\mathrm{CAD}$, which could contribute to a better understanding of the pathophysiology of atherosclerosis [2-5].

Another aspect of the applicability of our results is related to the primary and secondary prevention of CAD major events. $\mathrm{Lp}(a) \geq 50 \mathrm{mg} / \mathrm{dL}$ constitutes a risk-enhancing factor among primary prevention individuals [34] and is linked to a significantly higher incidence of subsequent MI in individuals with CAD [9]. Recently, Bittner et al. showed that $\mathrm{Lp}($ a) lowering by alirocumab was an independent contributor to major adverse cardiovascular events reduction [35], suggesting that $\mathrm{Lp}(a)$ may be an independent treatment target after acute coronary syndrome. In spite of these findings, the mechanisms underlying these observations have yet to be established.

One proposed mechanism for the role $\mathrm{Lp}(a)$ plays in atherogenesis involves the selective penetration and accumulation of apo $(a)$ at the arterial injury site. Some authors have proposed that this uptake is probably specific and mediated by platelets [36, 37]. Regarding atherothrombosis, it has been demonstrated that $\operatorname{Lp}(a)$ can compete with plasminogen for binding to the surface of fibrin [13]. Both $\operatorname{Lp}(a)$ and apo(a) could prevent plasminogen activation through a reduction in tissue-type plasminogen activator activity [13], thereby inhibiting intrinsic fibrinolysis and stimulating a prothrombotic pathway that leads to increased platelet reactivity (or, at least, reducing platelet disaggregation) $[38,39]$.

In vitro studies showed conflicting results regarding the association between high concentrations of $\operatorname{Lp}(a)$ and platelet reactivity, showing positive, negative, or neutral associations between the two variables. A positive correlation between $\operatorname{Lp}(a)$ and platelet reactivity was described by Rand et al. [17] and Martínez et al. [40] via thrombin receptor activating peptide (SFLLRN) and arachidonic acid, respectively. In contrast with these findings, other 

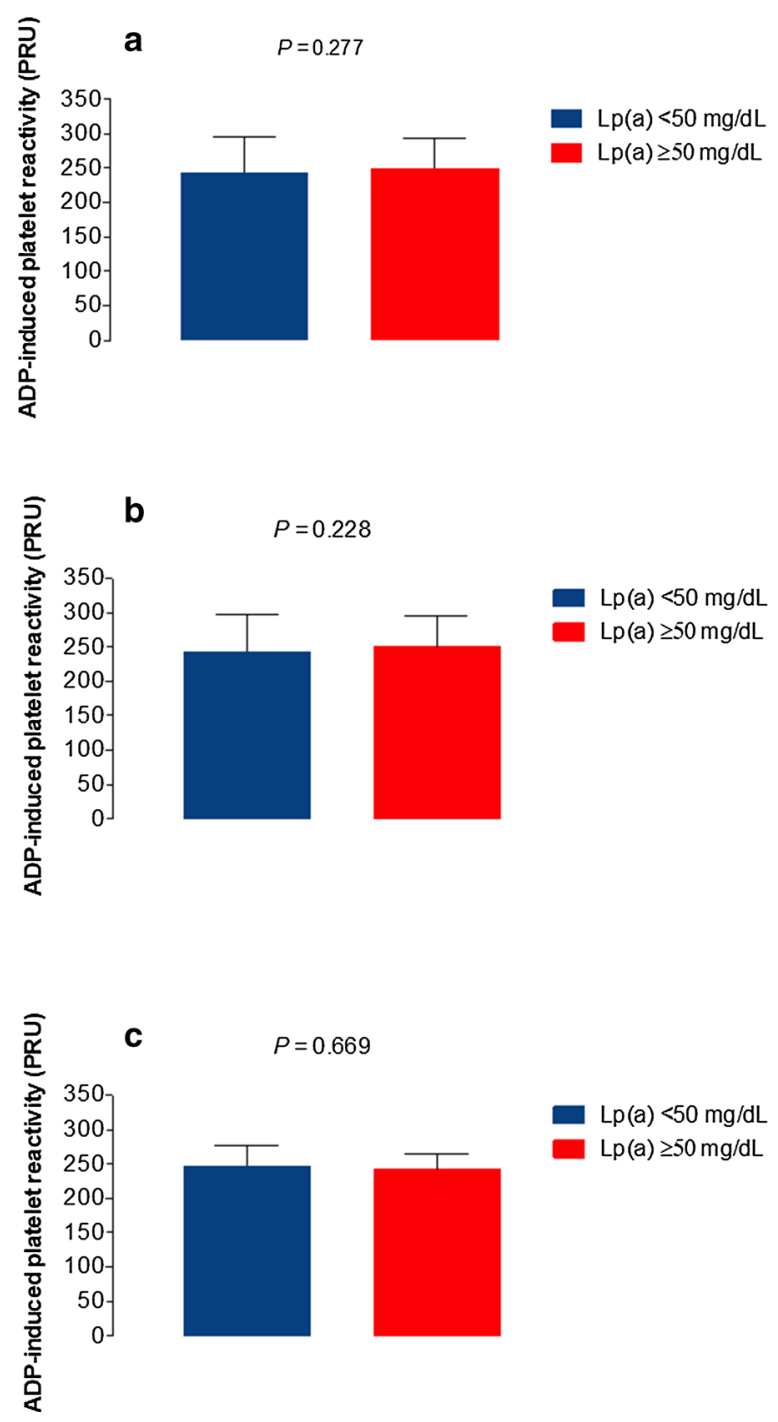

Fig. 2 Association of ADP-induced platelet reactivity according to lipoprotein (a) concentrations in individuals stratified by the presence or absence of CAD. Univariate analysis was applied to determine the association between $\mathrm{Lp}(a)$ concentrations $<50 \mathrm{mg} / \mathrm{dL}$ and $\mathrm{Lp} \geq 50 \mathrm{mg} / \mathrm{dL}$ versus $\mathrm{ADP}$-induced platelet reactivity measured by VerifyNow $^{\mathrm{TM}} \mathrm{P}^{\mathrm{P}} \mathrm{Y}_{12}$ (PRU) in a total of 396 individuals (a) which included 326 with CAD (b) and 70 without CAD (c). Values are median (IQR). $P$ value are from Mann-Whitney test (see "Methods"). ADP adenosine diphosphate, CAD coronary artery disease, $\mathrm{Lp}(a)$ lipoprotein (a), PRU $\mathrm{P} 2 \mathrm{Y}_{12}$ reaction units, IQR interquartile range

studies have shown significant reduction in collagen-induced platelet reactivity measured in whole blood or washed platelet co-incubated with high concentrations of $\operatorname{Lp}(a)$ from human donors, which were accompanied by decreasing of serotonin secretion and $\mathrm{TxB}_{2}$ production $[18,19,40,41]$. Additionally, elevated $\operatorname{Lp}(a)$ decreases ADP-induced platelet reactivity via the reduction of intracellular cyclic adenosine monophosphate (cAMP) or platelet-activating factor (PAF) [18, 42, 43]. Finally, similar to our results, no association was found between elevated concentrations of $\operatorname{Lp}(a)$ and platelet reactivity in response to platelet activation by thrombin [19], collagen [44], and ADP [17, 19] by other investigators.

To the best of our knowledge, only one study in vivo has been published to date analyzing the association between $\operatorname{Lp}(a)$ concentrations and platelet reactivity. In that study, Barre et al. [45] randomized 40 individuals with diabetes to flaxseed or safflower (placebo) oil. In a subset of 32 individuals, they demonstrated a Pearson correlation of $0.54(P<0.05)$ between $\operatorname{Lp}(a)$ and bleeding time, which was considered a surrogate for platelet reactivity. In our study of 396 individuals with or without CAD, no correlation was found between $\operatorname{Lp}(a)$ concentrations and the established measures of platelet reactivity induced by different agonists and different methods.

\section{Limitations}

The current study has several limitations. First, individuals with CAD were treated with aspirin. It has been reported that aspirin treatment may markedly potentiate the ability of tissue-type plasminogen activator activity to induce disaggregation [38], suggesting that aspirin could attenuate one of the mechanisms proposed for $\mathrm{Lp}(a)$-mediated platelet reactivity [13]. However, in individuals without CAD who were not taking aspirin, we also did not find any significant differences in arachidonic acid-induced platelet reactivity. On the other hand, the main objective of the present study was to evaluate a possible association between $\operatorname{Lp}(a)$ concentrations and platelet reactivity in response to ADP. The ADP-P2 $\mathrm{Y}_{12}$ pathway has stronger a association with ischemic events or mortality [22] and could be involved in the potential 
Table 3 Association between platelet reactivity and $\operatorname{Lp}(a)$ concentrations

\begin{tabular}{|c|c|c|c|c|}
\hline & $n$ & $\begin{array}{l}\mathrm{Lp}(a)<50 \mathrm{mg} / \\
\mathrm{dL}\end{array}$ & $\begin{array}{l}\mathrm{Lp}(a) \geq 50 \mathrm{mg} / \\
\mathrm{dL}\end{array}$ & $P$ values \\
\hline 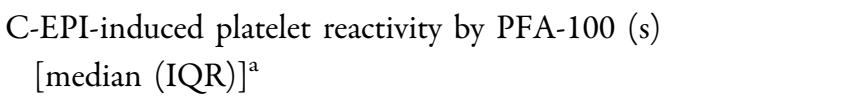 & 156 & $102.0(86.0-145.0)$ & $117(97.0-165.5)$ & 0.235 \\
\hline $\begin{array}{l}\text { Arachidonic acid-induced platelet reactivity by VerifyNow }{ }^{\mathrm{TM}} \\
\text { Aspirin (ARU) }[\text { mean }(\mathrm{SD})]^{\mathrm{a}}\end{array}$ & 130 & $530.0 \pm 80.4$ & $527.4 \pm 83.7$ & 0.819 \\
\hline $\begin{array}{l}\text { ADP-induced platelet reactivity by Multiplate }{ }^{\mathrm{TM}} \text { (AU min) } \\
\quad[\text { mean }(\mathrm{SD})]^{\mathrm{a}, \mathrm{b}}\end{array}$ & 152 & $73.2 \pm 23.4$ & $73.2 \pm 21.3$ & 0.996 \\
\hline $\begin{array}{l}\text { Arachidonic acid-induced platelet reactivity by Multiplate }{ }^{\mathrm{TM}} \\
(\mathrm{AU} \text { min })[\text { median }(\mathrm{IQR})]^{\mathrm{b}}\end{array}$ & 49 & $71.4 \pm 24.3$ & $76.1 \pm 26.9$ & 0.532 \\
\hline ADP-induced platelet reactivity by LTA (\%) $[\text { median (IQR) }]^{\mathrm{a}}$ & 130 & $80.6(74.1-84.5)$ & $75.1(70.5-82.8)$ & 0.112 \\
\hline Serum $\mathrm{TxB}_{2}(\mathrm{pg} / \mathrm{mL})$ levels $[\text { mean }(\mathrm{SD})]^{\mathrm{a}}$ & 59 & $208.6 \pm 59.6$ & $202.7 \pm 58.5$ & 0.770 \\
\hline
\end{tabular}

Values are expressed as mean $\pm \mathrm{SD}$ or median (IQR)

$L p(a)$ lipoprotein (a), PFA-100 platelet function analyzer $100^{\mathrm{TM}}, C-E P I$ collagen-epinephrine, $A R U$ aspirin reaction units, $A D P$ adenosine diphosphate, $A U$ area under the curve, min minutes, $L T A$ light transmission aggregometry, $T x B_{2}$ thromboxane $\mathrm{B}_{2}, I Q R$ interquartile range

$P$ values are from Student's $t$ test or Mann-Whitney test

a Individuals with CAD

b Individuals without CAD

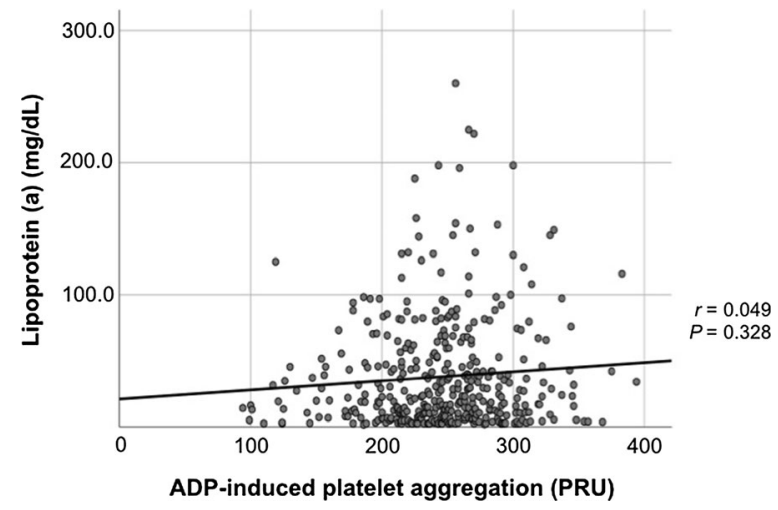

Fig. 3 Association between lipoprotein (a) concentrations and ADP-induced platelet reactivity. Linear regression was represented for $\mathrm{Lp}(a)$ measured in $\mathrm{mg} / \mathrm{dL}$ versus $\mathrm{ADP}$ induced platelet reactivity evaluated by VerifyNow ${ }^{\mathrm{TM}}$ P2Y 12 assay (PRU). Lp(a) lipoprotein (a), ADP adenosine diphosphate, PRU P2Y 12 reaction units

prothrombotic risk of $\operatorname{Lp}(a)$ for individuals in primary and secondary prevention $[8,23-26,34]$. Second, we did not assess the effect of $\operatorname{apo}(a)$ on platelet reactivity, which appears to have an additional effect on aggregation $[17,18,40]$. Third, we were unable to measure $\operatorname{Lp}(a)$ by isoform-independent assay, as this was not available in our laboratory. In this regard, some studies have argued that a significant correlation of $r=0.94$ between $\operatorname{Lp}(a)$ values measured in fresh and frozen samples proves that storage has no significant effect on the analysis and interpretation of data, as we observed in our results [46]. However, Kronenberg et al. found small but significant decrease in $\operatorname{Lp}(a)$ concentrations over time [47]. Fourth, despite this study being the largest to date, the lack of association could be due to a type 2 error. However, the numerically similar values for both groups of interest together with the multitude of different tests performed make it less likely that our study was underpowered. Additionally, if we consider 20 PRU as the minimal clinically relevant difference between the two groups in order to influence clinical 
outcomes, our study would have more than $95 \%$ power to detect such a difference. Nonetheless, we cannot rule out a smaller difference of uncertain clinical significance. Lastly, our CAD population was from a single center and included only individuals taking aspirin as the sole antiplatelet agent. However, our findings are consistent with prior reports [48], thus suggesting that our patients were well representative of a general population of patients with CAD.

\section{CONCLUSIONS}

Among a population that included individuals with and without CAD, concentrations of $\mathrm{Lp}(a) \geq 50 \mathrm{mg} / \mathrm{dL}$ were not associated with higher platelet reactivity. Further studies are needed to better clarify the pro-thrombotic mechanism related to $\operatorname{Lp}(a)$ in order to identify new strategies for $\operatorname{Lp}(a)$ lowering and associated reduction in cardiovascular risk.

\section{ACKNOWLEDGMENTS}

We are grateful to all participants for their cooperation in the study.

Funding. This work was supported by the Sao Paulo Research Foundation (Fundação de Amparo à Pesquisa do Estado de São Paulo (FAPESP) [grant numbers 2014/01021-4 (JCN), 2014/03742-0 (RCM)], São Paulo, Brazil. RS has a post-doctoral fellowship from FAPESP (2017/ 26922-2). No Rapid Service Fee was received by the journal for the publication of this article.

Authorship. All named authors meet the International Committee of Medical Journal Editors (ICMJE) criteria for authorship for this article, take responsibility for the integrity of the work as a whole, and have given their approval for this version to be published.

Disclosures. Remo H. M. Furtado reports grants and personal fees from AstraZeneca, personal fees from Servier, and grants from EMS, Pfizer, Novo Nordisk, DalCor, Novartis, and
Jansen, all of them outside the submitted work. Shaun G. Goodman receives research grant support (e.g., steering committee NovoNordisk, speaker board from NovoNordisk, Sanofi-Aventis, AstraZeneca, Eli Lilly, Boehringer Ingelheim and Abbott. Robert P. Giugliano reports grant support to his institution from Amgen, Daiichi Sankyo, and Merck, and honoraria for CME programs or consulting from Amarin, Amgen, Bristol Myers Squibb, CVS Caremark, Daiichi Sankyo, Merck, or data monitoring committee) and/or speaker/consulting honoraria (e.g., advisory boards) from Amgen, AstraZeneca, Bayer, Boehringer Ingelheim, Bristol Myers Squibb, CSL Behring, Daiichi Sankyo/American Regent, Eli Lilly, Esperion, Ferring Pharmaceuticals, GlaxoSmithKline, HLS Therapeutics, Janssen/Johnson \& Johnson, Merck, Novartis, Novo Nordisk A/C, Pfizer, Regeneron, Sanofi, Servier; and salary support from the Heart and Stroke Foundation of Ontario/University of Toronto (Polo) Chair, Canadian Heart Research Centre and MD Primer, Canadian VIGOUR Centre, Duke Clinical Research Institute, New York University Clinical Coordinating Centre, and PERFUSE. Paul A. Gurbel is a consultant and/or receives honoraria from Bayer, Merck, Janssen, Medicure and USWorld Meds; has also received grants from the NIH, Janssen, Merck, Bayer, Haemonetics, Instrumentation Labs and Amgen; and is also holding stock or stock options in Merck, Medtronic and Pfizer and holding patents in the area of personalized antiplatelet therapy and interventional cardiology. Jose C. Nicolau reports grants from Astra Zeneca, grants and personal fees from Bayer, grants from Bristol Myers Squibb, grants from CLS Behring, personal fees from Daiichi Sankyo, grants from Dalcor, grants from Boehringer Ingelheim, grants and personal fees from Novartis, grants from NovoNordisk, grants and personal fees from Sanofi, personal fees from Servier, grants from Vifor. Rocío Salsoso, Talia F. Dalcoquio, André Franci, Carlos J. D. G. Barbosa, Paulo R. R. Genestreti, Celia M. C. Strunz, Viviane Lima, Luciano M. Baracioli and Raul C. Maranhão have nothing to disclose. 
Prior Presentation. These data were presented, in part, at the American College of Cardiology's (ACC) 69th Annual Scientific Session together with the World Congress of Cardiology; March 28-30, 2020; Chicago, Illinois, USA.

Compliance with Ethics Guidelines. The protocols for this research were approved by the Ethics Committee of the Clinical Hospitals, University of Sao Paulo Medical School [Approval Numbers: Comissão de Ética para Análise de Projetos de Pesquisa (CAPPesq) do Hospital das Clinicas da Faculdade de Medicina da Universidade de São Paulo (HCFMUSP): 0136-11 (NCT01896557); Certificado de Apresentação para Apreciação Ética (CAAE): 05965412.0.0000.0068 (NCT02316119); CAAE: 35079514.8.0000.0068 (NCT03039205, NCT03632785)]. The study was performed in accordance with the declaration of Helsinki 1964 and its later amendments. All participants provided written informed consent to participate in the study.

Data Availability. The datasets generated and/or analyzed during the current study are available from the corresponding author on reasonable request.

Open Access. This article is licensed under a Creative Commons Attribution-NonCommercial 4.0 International License, which permits any non-commercial use, sharing, adaptation, distribution and reproduction in any medium or format, as long as you give appropriate credit to the original author(s) and the source, provide a link to the Creative Commons licence, and indicate if changes were made. The images or other third party material in this article are included in the article's Creative Commons licence, unless indicated otherwise in a credit line to the material. If material is not included in the article's Creative Commons licence and your intended use is not permitted by statutory regulation or exceeds the permitted use, you will need to obtain permission directly from the copyright holder. To view a copy of this licence, visit http://creativecommons.org/licenses/by$\mathrm{nc} / 4.0 /$.

\section{REFERENCES}

1. Borrelli MJ, Youssef A, Boffa MB, Koschinsky ML. New frontiers in $\operatorname{Lp}(a)$-targeted therapies. Trends Pharmacol Sci. 2019;40:212-25. https://doi.org/10. 1016/j.tips.2019.01.004.

2. Erqou S, Kaptoge S, Perry PL, et al. Lipoprotein $(a)$ concentration and the risk of coronary heart disease, stroke, and nonvascular mortality. JAMA. 2009;302:412-23. https://doi.org/10.1001/jama. 2009.1063 .

3. Clarke R, Peden JF, Hopewell JC, et al. Genetic variants associated with $\operatorname{Lp}(a)$ lipoprotein level and coronary disease. N Engl J Med. 2009;361:2518-28. https://doi.org/10.1056/NEJMoa0902604.

4. Rhoads GG, Dahlen G, Berg K, Morton NE, Dannenberg AL. $\operatorname{Lp}(a)$ lipoprotein as a risk factor for myocardial infarction. JAMA. 1986;256:2540-4. https://doi.org/10.1001/jama.1986. 03380180102027.

5. Sandkamp M, Funke H, Schulte H, Köhler E, Assmann G. Lipoprotein $(a)$ is an independent risk factor for myocardial infarction at a young age. Clin Chem. 1990;36:20-3.

6. Danesh J, Collins R, Peto R. Lipoprotein $(a)$ and coronary heart disease. Meta-analysis of prospective studies. Circulation. 2000;102:1082-5. https://doi. org/10.1161/01.cir.102.10.1082.

7. Nordestgaard BG, Chapman MJ, Ray K, et al. European Atherosclerosis Society Consensus Panel. Lipoprotein $(a)$ as a cardiovascular risk factor: current status. Eur Heart J. 2010;31:2844-53. https:// doi.org/10.1093/eurheartj/ehq386.

8. Sanchez Muñoz-Torrero JF, Rico-Martín S, Álvarez LR, Aguilar E, Alcalá JN, Monreal M. Lipoprotein (a) levels and outcomes in stable outpatients with symptomatic artery disease. Atherosclerosis. 2018;276:10-4. https://doi.org/10.1016/j. atherosclerosis.2018.07.001.

9. O’Donoghue ML, Fazio S, Giugliano RP, et al. Lipoprotein $(a)$, PCSK9 inhibition, and cardiovascular risk. Circulation. 2019;139:1483-92. https:// doi.org/10.1161/CIRCULATIONAHA.118.037184.

10. O'Donoghue ML, Morrow DA, Tsimikas S, et al. Lipoprotein $(a)$ for risk assessment in patients with established coronary artery disease. J Am Coll Cardiol. 2014;63:520-47. https://doi.org/10.1016/j. jacc.2013.09.042.

11. Zewinger S, Kleber ME, Tragante V, et al. Relations between lipoprotein $(a)$ concentrations, LPA genetic variants, and the risk of mortality in patients with 
established coronary heart disease: a molecular and genetic association study. Lancet Diabetes Endocrinol. 2017;5:534-43. https://doi.org/10.1016/ S2213-8587(17)30096-300107.

12. van der Valk FM, Bekkering S, Kroon J, et al. Oxidized phospholipids on lipoprotein $(a)$ elicit arterial wall inflammation and an inflammatory monocyte response in humans. Circulation. 2016;134:611-24. https://doi.org/10.1161/CIRCULATIONAHA.116. 020838 .

13. Ezratty A, Simon DI, Loscalzo J. Lipoprotein $(a)$ binds to human platelets and attenuates plasminogen binding and activation. Biochemistry. 1993;32:4628-33. https://doi.org/10.1021/ bi00068a021.

14. Ioka $\mathrm{T}$, Tasaki $\mathrm{H}$, Yashiro $\mathrm{A}$, et al. Association between plasma lipoprotein $(a)$ and endothelial dysfunction in normocholesterolemic and non-diabetic patients with angiographically normal coronary arteries. Circ J. 2002;66:267-71. https://doi. org/10.1253/circj.66.267.

15. Ouweneel AB, Van Eck M. Lipoproteins as modulators of atherothrombosis: from endothelial function to primary and secondary coagulation. Vascul Pharmacol. 2016;82:1-10. https://doi.org/10.1016/ j.vph.2015.10.009.

16. Palabrica TM, Liu AC, Aronovitz MJ, Furie B, Lawn RM, Furie BC. Antifibrinolytic activity of apolipoprotein $(a)$ in vivo: human apolipoprotein $(a)$ transgenic mice are resistant to tissue plasminogen activator-mediated thrombolysis. Nat Med. 1995;1:256-9. https://doi.org/10.1038/ nm0395-256.

17. Rand ML, Sangrar W, Hancock MA, et al. Apolipoprotein $(a)$ enhances platelet responses to the thrombin receptor-activating peptide SFLLRN. Arterioscler Thromb Vasc Biol. 1998;18:1393-9. https://doi.org/10.1161/01.atv.18.9.1393.

18. Barre DE. Lipoprotein (a) reduces platelet aggregation via apo $(a)$-mediated decreases in thromboxane A(2)production. Platelets. 1998;9:93-6. https://doi. org/10.1080/09537109876852.

19. Gries A, Gries M, Wurm H, et al. Lipoprotein $(a)$ inhibits collagen-induced aggregation of thrombocytes. Arterioscler Thromb Vasc Biol. 1996;16: 648-55. https://doi.org/10.1161/01.atv.16.5.648.

20. Cegla J, Neely RDG, France M, et al. HEART UK consensus statement on $\operatorname{lipoprotein}(a)$ : a call to action. Atherosclerosis. 2019;291:62-70. https:// doi.org/10.1016/j.atherosclerosis.2019.10.011.

21. Gargiulo G, Windecker S, Vranckx P, Gibson CM, Mehran R, Valgimigli M. A critical appraisal of aspirin in secondary prevention: is less more? Circulation. 2016;134:1881-906. https://doi.org/10. 1161/CIRCULATIONAHA.116.023952.

22. Stone GW, Witzenbichler B, Weisz G, et al. Platelet reactivity and clinical outcomes after coronary artery implantation of drug-eluting stents (ADAPTDES): a prospective multicentre registry study. Lancet. 2013;382:614-23. https://doi.org/10.1016/ S0140-6736(13)61170-8.

23. Séguro F, Bérard E, Bongard V, et al. Real life validation of the European Atherosclerosis Society Consensus Panel lipoprotein(a) threshold of $50 \mathrm{mg} /$ dL. Int J Cardiol. 2016;221:537-8. https://doi.org/ 10.1016/j.ijcard.2016.07.018.

24. Grundy SM, Stone NJ, Bailey AL, et al. 2018 AHA/ ACC/AACVPR/AAPA/ABC/ACPM/ADA/AGS/APhA/ ASPC/NLA/PCNA guideline on the management of blood cholesterol: a report of the American College of Cardiology/American Heart Association Task Force on Clinical Practice Guidelines. Circulation. 2019;139:e1082-143. https://doi.org/10.1161/CIR. 0000000000000625 .

25. Arnett DK, Blumenthal RS, Albert MA, et al. 2019 ACC/AHA guideline on the primary prevention of cardiovascular disease: a report of the American College of Cardiology/American Heart Association Task Force on Clinical Practice Guidelines. J Am Coll Cardiol. 2019;74:e177-232. https://doi.org/10. 1016/j.jacc.2019.03.010.

26. Wilson DP, Jacobson TA, Jones PH, et al. Use of lipoprotein $(a)$ in clinical practice: a biomarker whose time has come. A scientific statement from the National Lipid Association. J Clin Lipidol. 2019;13:374-92. https://doi.org/10.1016/j.jacl. 2019.04.010.

27. Scharnagl H, Stojakovic T, Dieplinger B, et al. Comparison of lipoprotein (a) serum concentrations measured by six commercially available immunoassays. Atherosclerosis. 2019;289:206-13. https://doi.org/10.1016/j.atherosclerosis.2019.08. 015.

28. Sibbing D, Aradi D, Alexopoulos D, et al. Updated expert consensus statement on platelet function and genetic testing for guiding P2Y12 receptor inhibitor treatment in percutaneous coronary intervention. JACC Cardiovasc Interv. 2019;12: 1521-37. https://doi.org/10.1016/j.jcin.2019.03. 034.

29. Larsen PD, Holley AS, Sasse A, Al-Sinan A, Fairley S, Harding SA. Comparison of Multiplate and VerifyNow platelet function tests in predicting clinical outcome in patients with acute coronary syndromes. Thromb Res. 2017;152:14-9. https://doi. org/10.1016/j.thromres.2017.02.006. 
30. Moenen FCJI, Vries MJA, Nelemans PJ, et al. Screening for platelet function disorders with Multiplate and platelet function analyzer. Platelets. 2019;30:81-7. https://doi.org/10.1080/09537104. 2017.1371290.

31. Jeong YH, Tantry US, Min JH, et al. Influence of platelet reactivity and inflammation on peri-procedural myonecrosis in East Asian patients undergoing elective percutaneous coronary intervention. Int J Cardiol. 2013;168:427-35. https://doi.org/10. 1016/j.ijcard.2012.09.132.

32. Furtado RHM, Giugliano RP, Dalcoquio TF, et al. Increased bodyweight and inadequate response to aspirin in individuals with coronary artery disease. J Thromb Thrombolysis. 2019;48:217-24. https:// doi.org/10.1007/s11239-019-01830-z.

33. Barbosa CJDG, de Souza Barreiros R, Franci A, et al. Platelet function, coagulation and fibrinolysis in patients with previous coronary and cerebrovascular ischemic events. Clinics (Sao Paulo). 2019;74: e1222. https://doi.org/10.6061/clinics/2019/e1222.

34. Madsen CM, Kamstrup PR, Langsted A, Varbo A, Nordestgaard B. Lipoprotein(a)-lowering by $50 \mathrm{mg} /$ $\mathrm{dL}(105 \mathrm{nmol} / \mathrm{L})$ may be needed to reduce cardiovascular disease $20 \%$ in secondary prevention: a population-based study. Arterioscler Thromb Vasc Biol. 2020;40:255-66. https://doi.org/10.1161/ ATVBAHA.119.312951.

35. Bittner VA, Szarek M, Aylward PE, et al. Effect of alirocumab on lipoprotein $(a)$ and cardiovascular risk after acute coronary syndrome. J Am Coll Cardiol. 2020;75:133-44. https://doi.org/10.1016/j. jacc.2019.10.057.

36. Nielsen LB, Stender S, Kjeldsen K, Nordestgaard BG. Specific accumulation of lipoprotein $(a)$ in ballooninjured rabbit aorta in vivo. Circ Res. 1996;78: 615-26. https://doi.org/10.1161/01.res.78.4.615.

37. Ryan MJ, Emig LL, Hicks GW, et al. Localization of lipoprotein $(a)$ in a monkey model of rapid neointimal growth. Arterioscler Thromb Vasc Biol. 1997;17:181-7. https://doi.org/10.1161/01.atv.17. 1.181.J.

38. Loscalzo J, Vaughan DE. Tissue plasminogen activator promotes platelet disaggregation in plasma. J Clin Invest. 1987;79:1749-55. https://doi.org/10. 1172/JCI113015.

39. Schafer AI, Zavoico GB, Loscalzo J, Maas AK. Synergistic inhibition of platelet activation by plasmin and prostaglandin I2. Blood. 1987;69:1504-7. https://doi.org/10.1182/blood.V69.5.1504.

40. Martínez C, Rivera J, Loyau S, et al. Binding of recombinant apolipoprotein $(a)$ to human platelets and effect on platelet aggregation. Thromb Haemost. 2001;85:686-93. https://doi.org/10.1055/s0037-1615654.

41. Pedreño J, Fernández R, Cullaré C, Barceló A, Elorza MA, de Castellarnau C. Platelet integrin alpha IIb beta 3 (GPIIb-IIIa) is not implicated in the binding of LDL to intact resting platelets. Arterioscler Thromb Vasc Biol. 1997;17:156-63. https://doi.org/ 10.1161/01.atv.17.1.156.

42. Barre DE. Apolipoprotein (a) mediates the lipoprotein (a)-induced biphasic shift in human platelet cyclic AMP. Thromb Res. 2003;112:321-4. https:// doi.org/10.1016/j.thromres.2004.01.002.

43. Tsironis LD, Mitsios JV, Milionis HJ, Elisaf M, Tselepis AD. Effect of lipoprotein (a) on platelet activation induced by platelet-activating factor: role of apolipoprotein (a) and endogenous PAF-acetylhydrolase. Cardiovasc Res. 2004;63:130-8. https://doi. org/10.1016/j.cardiores.2004.03.005.

44. Barre D. Human lipoprotein (a)-induced reduction of platelet aggregation is not mediated by apolipoprotein A's lysine-binding regions. Front Biosci. 2003;8:s1226-8. https://doi.org/10.1080/ 09537109876852 .

45. Barre DE, Griscti O, Mizier-Barre KA, Hafez K. Flaxseed oil and lipoprotein $(a)$ significantly increase bleeding time in type 2 diabetes patients in Cape Breton, Nova Scotia. Canada. J Oleo Sci. 2005;6:347-54. https://doi.org/10.5650/jos.54.347.

46. Ridker PM, Hennekens CH, Stampfer MJ. A prospective study of lipoprotein $(a)$ and the risk of myocardial infarction. JAMA. 1993;270:2195-9.

47. Kronenberg F, Trenkwalder E, Dieplinger H, Utermann G. Lipoprotein $(a)$ in stored plasma samples and the ravages of time. Why epidemiological studies might fail. Arterioscler Thromb Vasc Biol. 1996;16:1568-72. https://doi.org/10.1161/01.atv. 16.12.1568.

48. Virani SS, Brautbar A, Davis BC, et al. Associations between lipoprotein $(a)$ levels and cardiovascular outcomes in black and white subjects: the Atherosclerosis Risk in Communities (ARIC) Study. Circulation. 2012;125:241-9. https://doi.org/10. 1161/CIRCULATIONAHA.111.045120. 